\title{
APPENDIX 4
}

POST-TEST PROBABILITIES OF DM1 IN DIFFERENT PRE-TEST PROBABILITIES OF DM1 AND AT VARIOUS RESULTS OF TESTS FOR ABS WITH CONFIDENCE INTERVALS

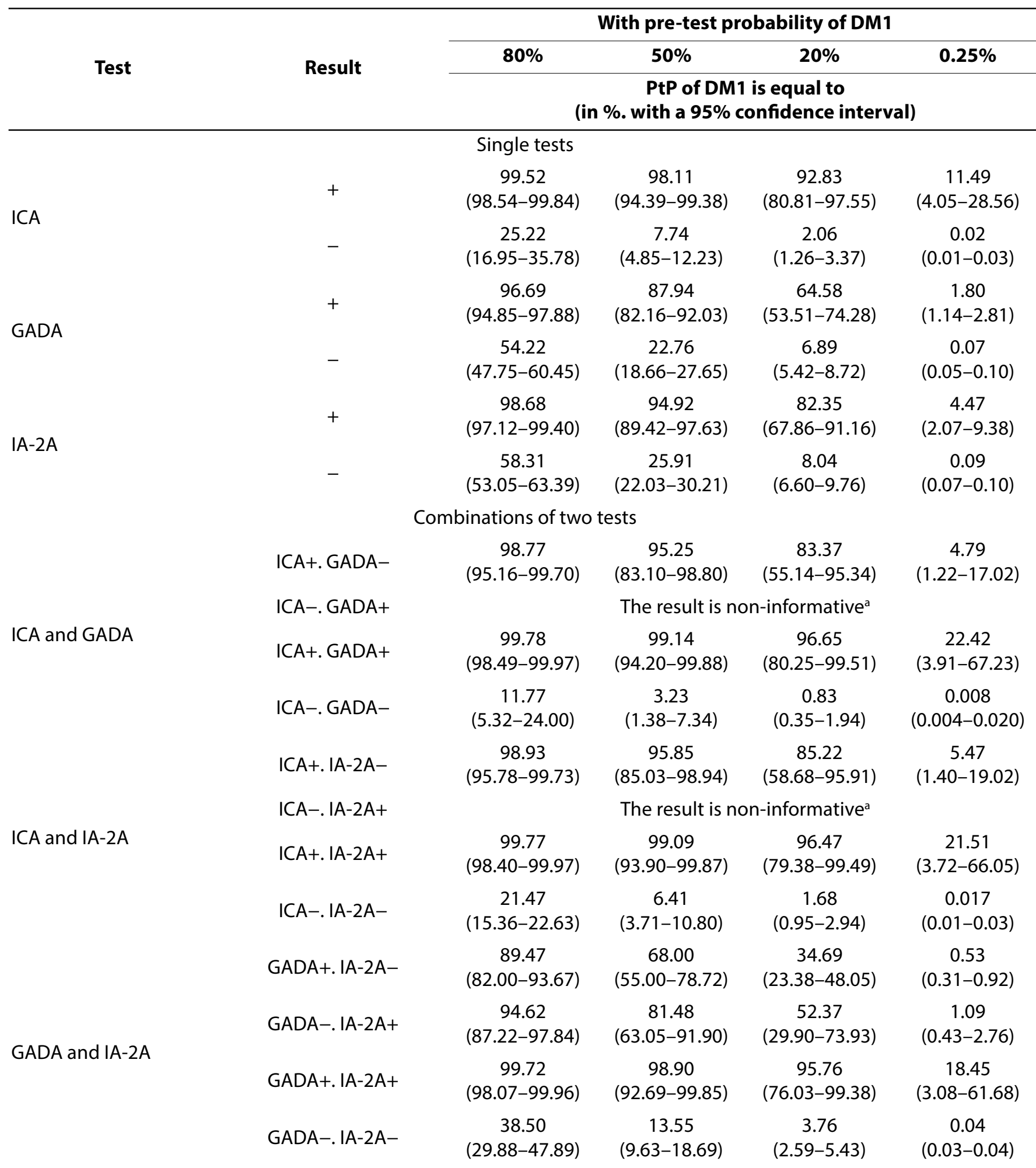




\begin{tabular}{|c|c|c|c|c|c|}
\hline \multirow{3}{*}{ Test } & \multirow{3}{*}{ Result } & \multicolumn{4}{|c|}{ With pre-test probability of DM1 } \\
\hline & & $80 \%$ & $50 \%$ & $20 \%$ & $0.25 \%$ \\
\hline & & \multicolumn{4}{|c|}{$\begin{array}{c}\text { PtP of DM1 is equal to } \\
\text { (in \%. with a } 95 \% \text { confidence interval) }\end{array}$} \\
\hline \multicolumn{6}{|c|}{ Combination of two tests } \\
\hline \multirow{8}{*}{$\begin{array}{l}\text { ICA and GADA and } \\
\text { IA-2A }\end{array}$} & ICA+. GADA-. IA-2A- & $\begin{array}{c}97.44 \\
(90.00-99.38)\end{array}$ & $\begin{array}{c}90.50 \\
(69.23-97.58)\end{array}$ & $\begin{array}{c}70.43 \\
(36.00-90.98)\end{array}$ & $\begin{array}{c}2.33 \\
(0.56-9.18)\end{array}$ \\
\hline & ICA-. GADA+. IA-2A- & \multicolumn{4}{|c|}{ The result is non-informative ${ }^{a}$} \\
\hline & ICA-. GADA-. IA-2A+ & \multicolumn{4}{|c|}{ The result is non-informative ${ }^{a}$} \\
\hline & $\mathrm{ICA}+. \mathrm{GADA}+. \mathrm{IA}-2 \mathrm{~A}-$ & $\begin{array}{c}99.09 \\
(93.69-99.87)\end{array}$ & $\begin{array}{c}96.44 \\
(78.78-99.50)\end{array}$ & $\begin{array}{c}87.13 \\
(48.13-98.02)\end{array}$ & $\begin{array}{c}6.36 \\
(0.92-33.12)\end{array}$ \\
\hline & ICA+. GADA-. IA-2A+ & $\begin{array}{c}99.616 \\
(97.16-99.95)\end{array}$ & $\begin{array}{c}98.446 \\
(89.52-99.79)\end{array}$ & $\begin{array}{c}94.036 \\
(68.10-99.15)\end{array}$ & $\begin{array}{c}13.646 \\
(2.10-53.81)\end{array}$ \\
\hline & ICA-. GADA+. IA-2A+ & \multicolumn{4}{|c|}{ The result is non-informative ${ }^{a}$} \\
\hline & $\mathrm{ICA}+. \mathrm{GADA}+. \mathrm{IA}-2 \mathrm{~A}+$ & $\begin{array}{c}99.72 \\
(98.02-99.96)\end{array}$ & $\begin{array}{c}98.88 \\
(92.54-99.84)\end{array}$ & $\begin{array}{c}95.66 \\
(75.61-99.37)\end{array}$ & $\begin{array}{c}18.11 \\
(3.02-61.15)\end{array}$ \\
\hline & ICA-. GADA-. IA-2A- & $\begin{array}{c}9.95 \\
(4.02-22.56)\end{array}$ & $\begin{array}{c}2.69 \\
(1.04-6.79)\end{array}$ & $\begin{array}{c}0.69 \\
(0.26-1.79)\end{array}$ & $\begin{array}{c}0.007 \\
(0.003-0.018)\end{array}$ \\
\hline
\end{tabular}

Notes: aThe result is non-informative. since it does not have DA (AUC does not differ significantly from 0.5 ). ${ }^{\circ}$ The calculations were made for DSpec equal to $99.8 \%$ (see explanation in the results section). 